




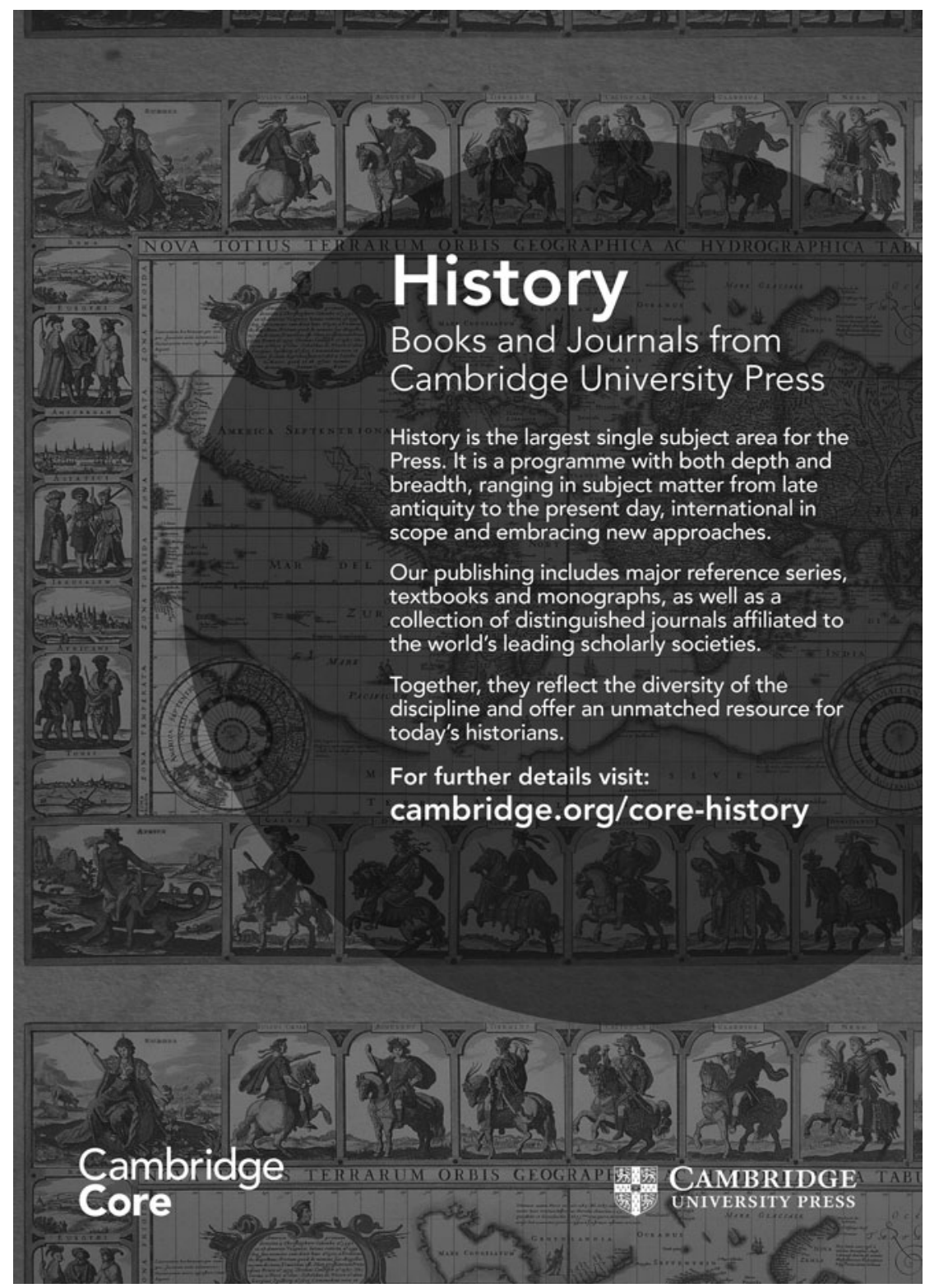




\section{EDITORIAL ADVISORY COMMITTEE}

GORDON M. BRADEN, University of Virginia CAMMY BROTHERS, Northeastern University TODD BUTLER, Washington State University MARSHA S. COLLINS, University of North

Carolina at Chapel Hill

SUSANNA DE BEER, Universiteit Leiden

ANGELA DRESSEN, Villa I Tatti, The Harvard University Center

ERIC R. DURSTELER, Brigham Young University WILLIAM E. ENGEL, University of the South EARLE A. HAVENS, Johns Hopkins University ROBERT HENKE, Washington University in St. Louis

TAMAR HERZIG, Tel Aviv University CARINA L. JOHNSON, Pitzer College DANA E. KATZ, Reed College ETHAN MATT KAVALER, University of Toronto DAVID A. LINES, Warwick University

EVAN A. MACCARTHY, West Virginia University
MIGUEL MARTÍNEZ, University of Chicago BRIAN JEFFREY MAXSON, East Tennessee State

University

SUSANNAH B. MONTA, University of Notre Dame JOSEPH M. ORTIZ, University of Texas at El Paso ALEJANDRA B. OSORIO, Wellesley College JAMES A. PARENTE JR., University of Minnesota CAROLINE PETIT, University of Warwick KAYA ŞAHIN, Indiana University Bloomington ELIZABETH SKERPAN-WHEELER, Texas State University, San Marcos ELEONORA STOPPINO, University of Illinois at Urbana-Champaign MIHOKO SUZUKI, University of Miami RAMIE TARGOFF, Brandeis University PHILIP JOHN USHER, New York University ALEXANDRA WALSHAM, University of Cambridge BRONWEN WILSON, University of California, Los Angeles 




CAMBRIDGE UNIVERSITY PRESS 